\author{
Cadernos de \\ ESTUDOS LINGUISTIICOS - (58.1), Campinas, pp. 93-111 - jan./abr. 2016
}

\title{
LÍNGUA, CULTURA E IMAGINÁRIOS: SINGULAR E PLURAL EM CONFLITO NOS MATERIAIS DIDÁTICOS DE PORTUGUÊS PARA ESTRANGEIROS
}

\author{
LUCIANA SALAZAR SALGADO ${ }^{1}$ \\ HELENA BOSCHI ${ }^{2}$
}

\begin{abstract}
RESUMO: Partindo de uma perspectiva discursiva em diálogo com pesquisas recentes da sociolinguística e da linguística aplicada, temos como objetivo investigar a construção e a difusão de imaginários de língua e de cultura, focalizando o primeiro livro da coleção Brasil Intercultural (Ciclo Básico, nível 1 e 2 - MOREIRA; BARBOSA; CASTRO, 2014). São examinadas, assim, propostas de atividade. Os dados mostram um conflito entre um posicionamento progressista e um posicionamento conservador ao longo do material, o que, segundo nossa hipótese, é um efeito da circulação de discursos no espaço público: enquanto estudos da linguagem mostram cada vez mais a complexidade das estruturas linguísticas e da diversidade de usos em conjunturas variadas, no mercado editorial, os próprios autores e o público consumidor são atravessados por um imaginário de língua e de cultura que estabelece uma relação biunívoca entre elas, calcada na noção de que uma língua é um código estável característico das trocas definidoras de um território nacional.
\end{abstract}

PALAVRAS-CHAVE: português brasileiro; interlíngua; imaginários.

RESUMEN: A partir de una perspectiva discursiva en diálogo con investigaciones recientes en sociolingüística y en lingüística aplicada, nuestro objetivo es investigar la construcción y la difusión de imaginarios de lengua y de cultura, haciendo foco en el primer libro de la colección Brasil Intercultural (Ciclo Básico, nivel 1 y 2 - MOREIRA; BARBOSA; CASTRO, 2014). De esta forma, analizamos las propuestas de actividades. Los datos muestran un conflicto entre un posicionamiento progresista y un posicionamiento conservador a lo largo del material, lo que, según nuestra hipótesis, es un efecto de la circulación de discursos en el espacio público: mientras estudios del lenguaje muestran cada vez más la complejidad de las estructuras lingüísticas y de la diversidad de usos en coyunturas variadas, en el mercado editorial, los propios autores y el público consumidor son atravesados por un imaginario de lengua y de cultura que establece una relación biunívoca entre éstas, calcada de la noción de que una lengua es un código estable característico de los intercambios que definen un territorio nacional.

PALABRAS-LLAVE: portugués brasileño; interlengua; imaginários.

${ }_{1}$ Professora na UFSCar, coordenadora dos Grupos de Pesquisa Comunica - inscrições linguísticas na comunicação (UFSCar/CNPq) e Escritas Profissionais e Processos de Edição (CEFETMG/CNPq).email: lucianasalazar@ufscar.br

${ }^{2}$ Doutoranda no Programa de Pós-Graduacão em Linguística PPGL da UFSCar, bolsista FAPESP (Processo 2015/01368-7), professora de português brasileiro como língua estrangeira. email: helenaboschi@gmail.com 


\section{INTRODUÇÃO}

Estas reflexões consideram como pano de fundo a acirrada discussão sobre o que há de certo e o que há de errado nos usos de uma língua, da qual faz parte a posição de que não há possibilidade de se postular certo e errado sem definição de parâmetros conjunturais, constituída em relação à posição que homologa uma língua e uma norma padrão, entre outras restrições que supõem um código bastante estabilizado. Possivelmente caberá considerar que há uma posição descritivista e outra prescritivista, para dizer o mínimo sobre dois olhares que se opõem, e que, havendo hegemonia desta última, estabelece-se uma desigualdade fundamental, que dá guarida a outras: "a língua a ser falada" se impõe sobre variantes e registros, apagando a pluralidade e, assim, identidades.

Diante disso, propõe-se, aqui, considerar a língua de uma perspectiva discursiva, com apoio no quadro teórico que supõe sua autonomia relativa, isto é, que os sentidos se produzem no encontro entre material linguístico e institucionalidades, sendo estas estabelecidas historicamente, conforme a circulação dos textos numa dada organização social. Em linhas gerais, podese dizer que essa perspectiva implica uma certa noção de sujeito - um tanto assujeitado às coerções em que se institui, um tanto impelido a manobras singulares -, uma certa noção de história - em que o presente se define no encontro de diversas temporalidades, na imbricação de acontecimentos discursivos de durações distintas - e uma certa noção de língua, decorrente opaca, é mobilizada sempre conforme relações parafrásticas que balizam os sentidos numa dada comunidade.

Importa registrar, ainda, que essa perspectiva impõe considerar a inscrição material dos dizeres, que só circulam textualizados em superfícies, plataformas ou suportes (diferentes teorias propõem diferentes visadas para essas materialidades), que não são inertes, nem transparentes, nem inócuas (cf. SALGADO, 2011).

Neste estudo, focalizamos materiais de ensino de língua, mais especificamente do ensino de português como língua estrangeira. Entendemos que esse é um posto privilegiado de observação da discussão acima referida e, ao definir como córpus a coleção Brasil Intercultural (Ciclo Básico, nível 1 e 2 - MOREIRA; BARBOSA; CASTRO, 2014) e como fonte dos dados postos em análise neste momento o primeiro livro da série, temos o objetivo dar início a uma investigação sobre os imaginários de língua e de cultura que aí se atualizam, participando fortemente das discursivizações sobre o tema. Nesta ocasião, damos relevo a um aspecto desse debate: o conflito entre singular e plural, que, no caso em tela, emerge em um material de caráter instrucional, portanto disciplinador, que se apresenta como compreensivo de uma diversidade irredutível. 
PERSPECTIVA TEÓRICA

Conforme os fundamentos acima explicitados, entende-se que, para a análise do discurso dita de tradição francesa, nossa leitura de mundo e, por conseguinte, dos referentes que atribuímos às palavras nas redes de sentido que tecemos entre elas é balizada pelos grupos a que pertencemos, pelos discursos que frequentamos. Os enunciados materializam o que pode e deve ser dito a partir de um dado lugar discursivo, social e historicamente construído. São encarnações parafrásticas de discursos que se atualizam a cada tomada de palavra, com o poder de estabilizar memórias ou de definir novas fronteiras em um universo interdiscursivo. Nessa perspectiva, os livros didáticos (LDs) de português brasileiro como língua estrangeira são também construção de sentidos sobre o que é essa língua e quem são seus falantes, resgatados no repertório interdiscursivo dos agentes da cadeia de produção editorial. Como toda publicação desse tipo, passam por um conjunto de mediações que, a cada decisão, vão dando forma ao produto final. Por isso,

cada autor, ao criar seus próprios textos e ao selecionar textos de outros autores para inclusão nas lições/unidades do material de ensino que elabora, recorre a representações do objeto focalizado (no caso, da identidade articulada à língua e à cultura-alvo) que são compartilhadas por seu grupo social, e, ao mesmo tempo, dá insumo para que o leitor, inscrito nesse ou em outro grupo social, possa construir suas próprias representações dessa identidade. (JÚDICE, 2013, p.3, destaques nossos)

Acrescentamos a isso que não somente autores, mas também organizadores, editores, revisores, produtores executivos, ilustradores, capistas, entre outros, atuam diretamente nos sentidos produzidos no objeto editorial. A importância que obras editadas e chanceladas por editoras adquirem na produção e na circulação de discursos, legitimando imaginários que se definem em redes interdiscursivas - por definição, tecidas por relações de poder -, é considerada por historiadores como Chartier na inextricável relação entre práticas e instituições sociais, na qual toda obra está ancorada, e que, portanto

compreender os princípios que governam "a ordem do discurso" pressupõe decifrar, com todo o rigor, aqueles outros que fundamentam os processos de produção, de comunicação e de recepção dos livros (e de outros objetos que veiculem o escrito). (CHARTIER, 1998, p.8, destaque nosso)

No caso de materiais que visam ao ensino de língua estrangeira, a simulação de situações reais de comunicação só pode se dar em relação a uma conjuntura muito específica de pertencimentos identitários, e as questões relativas à leitura de mundo emergem aí muito agudamente, das mais diferentes formas. $\mathrm{O}$ acesso que o estudante, um "estrangeiro", tem ao outro, o "falante nativo", se remete ao acesso a uma determinada identidade nacional, o que muitas vezes apaga o fato de que os enunciados sempre são produzidos a partir de um dado lugar discursivo, delimitado por outros territórios, com seus traços locais. Ao constar em um material didático, as nuances que envolvem as diversas formas de habitar uma 
língua e que se vinculam, necessariamente, a imaginários específicos de língua e de país (frequentemente homologados com a ideia de nação), correm o risco de ser lidas como consensos plenos, se os posicionamentos assumidos no processo de sua produção não estiverem bem delimitados. Na Gramática brasileña para hablantes de español (CARVALHO; BAGNO, 2015), por exemplo, a variedade adotada é definida e justificada logo na introdução. As regras de uso são contextualizadas a partir de dados reais do Banco Brasileiro (LAEL/PUC-SP) e de textos variados coletados na internet ou outros centros de investigação linguística. Mas, na maior parte dos casos, os materiais didáticos não se ocupam disso.

De todo modo, ao se propor um material de ensino de "português brasileiro" e de "cultura brasileira", necessariamente se assume algum lugar que é definido conforme o que se entende dessas categorias. Para Bagno, trata-se da condição inescapável da língua como hipóstase (e cremos poder pensar, também, na cultura como tal), ou seja, como objeto que personificamos como sujeito de qualidades e ações próprias. Segundo o autor,

não há remédio: para se falar de uma língua, é preciso construí-la, fabricá-la, forjá-la, dar um nome a ela, atribuir-lhe propriedades, características, índole. E esse é um trabalho empreendido não somente pelo linguista, em suas pretensões de objetividade científica, mas também (e talvez sobretudo) pelos falantes comuns, em suas práticas de higiene verbal, de mitificação e mistificação coletiva dos bens simbólicos, de construção do imaginário social acerca da própria cultura a que pertencem e dos mitos de origem que lhe dão raízes históricas e memória comum. (BAGNO, 2011b, p.357)

Ensinar "o" português brasileiro é, segundo esse entendimento, ensinar um dado recorte de tudo o que se poderia considerar como parte dessa língua. A decisão, como todas elas, não é feita sem atravessamentos: a hegemonia das gramáticas tradicionais, sabidamente elitizadas e herdeiras de práticas colonizadoras na abordagem da sistematização linguística, em detrimento da descrição dos fenômenos de linguagem conforme os usos constatados em pesquisas, é sintomática da desigualdade com que variantes forjadas em um ou outro contexto social são tratadas.

Ora, se vemos a língua como inscrita nos usos e partilhas, nas convenções e insubordinações de uma atividade linguageira, entendemos que se trata de consenso firmado sempre numa comunidade de falantes, na qual diversos registros linguísticos se formulam num jogo de forças histórico; entendemos, então, que a língua em uso delimita lugares e necessariamente dizeres e modos de dizer mutuamente implicados. Essa implicação, estribada sempre no pertencimento a grupos nos quais uma identidade se institui, forja o que se poderia referir como "seu próprio código", com as relações parafrásticas que esse pertencimento requer para que ele próprio se configure. Em todo caso, importa frisar que, por se tratar de língua, não se pode pensar em "código" simplesmente: há uma dinâmica linguageira em que radica a conjunção dos dizeres e modos de dizer, e essa dinâmica se formula interdiscursivamente, no encontro e no confronto entre diferentes discursivizações. 
Cadernos de ESTUDOS LINGUÍSTICOS (58.1) - jan./abr. 2016

É com base nisso que, desde Gênese dos Discursos (1984), Dominique Maingueneau vem formulando a noção de interlíngua, ultrapassando as noções correntes de intertextualidade e de interdiscurso ao articular os códigos linguageiros à semântica global das enunciações. Isso implica considerar que as práticas discursivas são conjuntos temáticos indissociáveis de conjuntos formais, os quais são indissociáveis de práticas outras, não-discursivas, diante do quê,

distinguir o fundamental do superficial, o essencial do acessório leva a um impasse, na medida em que é a significância discursiva em seu conjunto que deve ser visada em seu conjunto. Não pode haver fundo, 'arquitetura' do discurso, mas um sistema que investe o discurso na multiplicidade de suas dimensões (MAINGUENEAU, 2005, p. 80).

E não há planos privilegiados, uma vez que o eventual privilégio de algum deles é já um efeito de sentido que encontrará ratificações em outros planos, como a falta de relevo de certos outros, pois "o sistema de restrições define tanto uma relação com o corpo, com o outro... quanto com ideias, é o direito e o avesso do discurso, toda uma relação imaginária com o mundo" (p. 101). Os códigos linguageiros são, dessa perspectiva, as regiões da interlíngua mobilizadas nos textos, estruturantes do sistema de restrições.

No Dicionário de Análise do Discurso (MAINGUENEAU; CHARAUDEAU, 2008) inscreve-se esse conceito em dois domínios, a saber, a didática das línguas estrangeiras e a análise do discurso. Para a linguística aplicada, a interlíngua é "a língua utilizada por aprendizes que não dominam ainda uma língua estrangeira; é uma realidade provisória e instável, entre duas línguas, mas em relação à qual se postula que tem uma coerência relativa" (p.287). Para a análise do discurso, a interlíngua resulta "da interação das línguas e dos registros ou das variedades de língua acessíveis - tanto no espaço como no tempo - em uma conjuntura determinada" (p.97).

O ponto nevrálgico em que as duas abordagens divergem é a primeira pressupor existir um "estágio final" de língua acabada e bem delimitada, a "línguaalvo" a ser adquirida pelo estudante estrangeiro. Para a abordagem discursiva, falar sobre língua é necessariamente construir um imaginário sobre o que só se pode apreender em processo, na enunciação. Trata-se de um paradoxo constitutivo: "é por seu próprio enunciado que um fiador deve legitimar sua maneira de dizer" (MAINGUENEAU, 2002: s/p).

Seguindo esse raciocínio, a noção de interlíngua que mobilizamos supõe que não há um uso ou usos "da" língua: a norma culta ou a norma padrão, aquilo que se considera default ou o que se define como idioma oficial não estão à disposição de usuários que, tomando essas referências, podem desdobrá-las conforme sua vontade; a língua não é exterior e posterior à formulação de um algo a dizer: ela é constitutiva dos dizeres. Trata-se, então, de pensar que todo texto estabelece um código linguageiro próprio e que

Associam-se estreitamente nessa noção as acepções de "código" como sistema de regras e de signos que permite uma comunicação e de "código" como conjunto de prescrições: por definição, o uso da língua que a obra implica se apresenta como a maneira pela qual se tem de enunciar, por ser esta a única maneira compatível com o universo que ela [a obra] instaura (MAINGUENEAU, 2006, p. 182). 
Tendo isso em vista numa conjuntura em que o interesse pelo português brasileiro e o que se convencionou chamar cultura brasileira aumenta consideravelmente em nível mundial - o que pode ser constatado em notícias ${ }^{3}$, fatos $^{4}$ e pesquisas diversas ${ }^{5}$ - interessa-nos estudar os materiais didáticos como dispositivos históricos, para investigar a construção de língua e de cultura que é disponibilizada aos estudantes estrangeiros.

Para tanto, focalizamos, neste artigo, o livro de textos (volume destinado ao uso em sala de aula) do ciclo básico da coleção Brasil Intercultural: língua e cultura brasileira para estrangeiros (MOREIRA; BARBOSA; CASTRO, 2014), publicado pela Casa do Brasil de Buenos Aires e utilizado por instituições argentinas e uruguaias. Essa coleção é composta por três $\operatorname{ciclos}^{6}-$ básico, intermediário e avançado - com dois níveis cada, e cada ciclo tem um único livro de textos mais um livro de exercícios.

Examinando textos-base e atividades correspondentes, procuramos verificar, como foi dito, de que modo se constroem imaginários de língua e de cultura. Os dados desta análise inicial procuram mostrar uma diversidade de ocorrências que apontam para um convívio de posicionamentos discursivos distintos, principalmente no que tange à sistematização linguística: embora haja declarações por parte do coletivo responsável pela publicação a respeito da necessidade de abordar a diversidade linguística e cultural, as propostas de exercício e as explicações gramaticais desvelam um construto teórico conservador sobre os fatos da linguagem.

\section{SINGULAR E PLURAL EM CONFLITO}

Muitos esforços foram feitos nos vários domínios das Ciências Humanas para se delinearem as possibilidades e os limites de sentido do que seja "cultura". Justamente por poder ser considerada como "tudo o que é produzido pelo ser humano" (VANUCCHI, 2002), esse tema ocupa uma posição privilegiada nos

\footnotetext{
${ }^{3}$ Como, por exemplo, em "Brasil em alta impulsiona ensino de português no mundo", na BBC Brasil. Disponível em:

http://www.bbc.co.uk/portuguese/noticias/2012/10/120926_portugues_cursos_ru.shtml. Acesso em 25 de setembro de 2014.

${ }^{4}$ Segundo o Manual do Aplicador do exame de proficiência em português brasileiro, Celpe Bras (BRASIL, 2011, p.39-48), existem hoje 28 países com postos cadastrados para atender à crescente demanda pelo certificado, em contraposição a um único posto aplicador no exterior em 2002 (BRASIL, 2002, p. 25).

${ }^{5}$ Esse crescente interesse visto em nosso período pode ser explicado pelo que Gilvan Müller de Oliveira, diretor do Instituto Internacional da Língua Portuguesa (IILP/CPLP - Cabo Verde), considera como a terceira fase do português no "mundo globalizado", que colocou o Brasil em uma posição de destaque nas relações internacionais entre os países: "esta última fase assistiu à emergência do Brasil como potência regional, com atuação global em alguns âmbitos, participando dos BRICS (Brasil, Rússia, Índia, China e África do Sul), conjunto dos grandes países em território e população hoje responsáveis por uma parte importante do crescimento econômico do mundo" (OLIVEIRA, 2013). Cf. também, "Declinando a língua pelas injunções do mercado: institucionalização do português língua estrangeira (PLE)" (ZOPPI FONTANA; DINIZ, 2008).

${ }^{6}$ Está previsto o lançamento de um quarto ciclo, avançado superior, também com dois níveis, em julho de 2016.
} 
Cadernos de ESTUDOS LINGUÍSTICOS (58.1) - jan./abr. 2016

mais variados debates do espaço público: cultura de massas x cultura erudita, sociedade e "barbárie" (ELIAS, [1939] 2011), mundialização e interculturalidade em nível mundial (MATTELART, 2005), políticas linguísticas (LAGARES; BAGNO, 2011), culturais, multi, inter, transculturalidade (SALOMÃO, 2015; KRAMSCH, 2011b; LIDDICOAT, 2011; WELSCH, 1994; BYRAM, 2014). O historiador De Certeau, em A cultura no plural ([1993] 2012, p.193-194), distingue seis possibilidades de emprego de "cultura":

a. os traços do homem "culto", isto é, segundo o modelo elaborado nas sociedades estratificadas por uma categoria que introduziu suas normas onde ele impôs seu poder.

b. um patrimônio das "obras" que devem ser preservadas, difundidas ou com relação ao qual se situar (por exemplo, a cultura clássica, humanista, italiana ou inglesa etc.). À ideia de "obras" que devem ser difundidas acrescenta-se a de "criações" e de "criadores" que devem ser promovidos, em vista de uma renovação de patrimônio.

c. a imagem, a percepção ou a compreensão do mundo próprio a um meio (rural, urbano, nativo etc.) ou a uma época (medieval, contemporânea etc) (...).

d. comportamentos, instituições, ideologias e mitos que compõem quadros de referência e cujo conjunto, coerente ou não, caracteriza uma sociedade como diferente das outras. (...)

e. a aquisição, enquanto distinta do inato. A cultura diz respeito aqui à criação, ao artifício, à ação, em uma dialética que a opõe e a associa à natureza.

f. um sistema de comunicação, concebido segundo os modelos elaborados pelas teorias da linguagem verbal. Enfatizam-se sobretudo as regras que organizam entre si os significados, ou, em uma problemática próxima, a mídia (cf. A. Moles).

Falar sobre "cultura" pressupõe, assim, uma transitividade: cultura em relação a que aspecto do ser humano, do estar no mundo, das relações tecidas em uma dada sociedade?

No ensino de línguas, após a segunda guerra mundial aconteceram mudanças paradigmáticas no ensino estrutural tradicional. Se anteriormente "cultura" se associava somente às grandes obras da literatura, aos grandes episódios históricos (KRAMSCH, 2011a) - a Cultura com "C" maiúsculo, os itens $a$ e $b$ propostos por De Certeau -, a partir de então, a intensificação do comércio e da comunicação entre os países direciona a área a abordagens de viés comunicativo. Essa nova perspectiva leva ao crescimento dos trabalhos interessados na relação indissociável entre língua e cultura e à explicitação do "ensino da cultura" - aí inclusa a "cultura" com "c" minúsculo, dos hábitos do dia a dia - em cursos (KUMARAVADIVELU, 2008; SALOMÃO, 2015), levando à cristalização do termo língua-cultura.

Predomina o que Holliday (2001, p.38) considera como "visão essencialista" da cultura, vista como "a caraterística essencial de uma determinada nação", que se associa diretamente a um imaginário de língua nacional. Herdeira do nacionalismo do século XIX e do processo de consolidação dos Estados-nação na Europa, ela é, ainda hoje, a base de sustentação das políticas voltadas à unidade nacional na educação e nas mídias em todo o mundo, cujos exemplos modelares se constelam no modo de funcionamento de instituições como o Instituto Cervantes, a Real Academia Española, a Aliança Francesa, as Casas do Brasil, etc. 
Esse é o enquadramento dado à noção de língua e de cultura na maior parte dos materiais didáticos hoje, e a coleção Brasil Intercultural não é diferente nesse sentido. Na "Apresentação", a organizadora da coleção e os produtores executivos afirmam que

(...) o material é destinado ao(à) aluno(a) que quer aprender o português do Brasil tal como ele é, rico e diversificado, ambientado dentro da cultura que o marca e que ao mesmo tempo é marcado por ela. Nesse sentido, aprender o português através da coleção Brasil Intercultural significa conhecer e viver a língua-cultura brasileira, considerando as suas características e a sua relação com as outras culturas que, conjuntamente, conformam a(s) identidade(s) latinoamericana(s). (MENDES; MULLER; FOLSTER apud MOREIRA; BARBOSA; CASTRO, 2014, s/p, destaque nosso)

Nos termos discursivos que delimitamos acima, conceber um imaginário nacional homogêneo de língua e de cultura é necessariamente produzi-lo como efeito de um processo de significação, mais especificamente de apagamentos, recurso comum à simplificação e à didatização de conteúdos. Embora o produto apareça como unidade, do ponto de vista de sua recepção, o que é mostrado deixa entrever negociações entre discursos distintos e decisões dos sujeitos que atuam na cadeia editorial - note-se que assinam a apresentação a coordenadora e os produtores executivos, instâncias que respondem pelo material posto em circulação, instâncias autorais (SALGADO, 2011).

Ao definir o material como um meio de acesso ao "português do Brasil tal como ele é", a proposta se baseia em uma concepção transparente de língua una (e de nação, talvez) que contradiz a "riqueza" e a "diversidade" pretendidas, constituindo um nó cujos fios, segundo nossa hipótese, se emaranham entre um posicionamento conservador predominante e um posicionamento progressista que todavia se impõe, tanto em termos de imaginário de língua (e de seu ensino) quanto do que seja constituída "a cultura brasileira".

Os índices de inclusão do feminino e as marcas opcionais de plural (com o recurso aos parênteses) ratificam essa interpretação. Aparecem aí os debates postos no espaço público sobre gênero e identidade; um material que se propõe "intercultural" é chamado a assumir um posicionamento nas formas linguísticas que o marcam, eventualmente a despeito de critérios de legibilidade - o que é ainda mais fortemente constatável na seguinte passagem, mais à frente no texto da Apresentação: "professor(e)(a)s e aluno(a)(s) passam a ser mediador(e)(a) (s) culturais, sujeitos ativos e conscientes de seus papéis dentro do processo" (MOREIRA; BARBOSA; CASTRO, 2014, s/p). Quanto às possibilidades de leitura dadas pelo possível acréscimo do plural em "identidade(s) latino-americana(s)", sintetizam o conflito entre a assunção do diverso e sua homogeneização: não se assumiu o plural, oferecendo-se a dupla leitura, sugerindo-se que o singular não dá conta, que não há apenas uma identidade latino-americana, que é preciso levar em conta uma pluralidade. Mas, se é preciso fazê-lo, a que se deveria a necessidade de manter o singular? 
Essas ocorrências indiciam a circulação dos discursos no espaço público: enquanto estudos da linguagem mostram cada vez mais a complexidade das estruturas linguísticas e de seus usos em conjunturas variadas, necessariamente atreladas a pertencimentos identitários de diversas ordens, no mercado editorial, os próprios autores e o público consumidor são atravessados por um imaginário de sistema plenamente estável, que dê segurança em relação à predição dos comportamentos linguísticos e culturais, como já apontava Dahlén (1997, apud DERVIN, 2014) ${ }^{7}$.

Os dois posicionamentos podem ser verificados ao longo do livro que analisamos. Ainda na Apresentação, afirma-se o seguinte:

\begin{abstract}
A abordagem pedagógica adotada pela Coleção é intercultural, visto que está centrada em uma visão de língua como lugar de interação, como dimensão mediadora das relações que se estabelecem entre sujeitos e mundos culturais diferentes. A língua, desse modo, não significa apenas forma ou sistema, mas um conjunto de possibilidades de interação e vivência que inclui não só estruturas formais e suas regras, mas também todos os significados sociais, culturais, históricos e políticos que a constituem. (MENDES; MULLER; FOLSTER apud MOREIRA; BARBOSA; CASTRO, 2014, destaque nosso)
\end{abstract}

Nesse excerto, também é possível reconhecer as contribuições das diversas áreas da linguística, desde o entendimento de língua como sistema até a virada discursiva que passa a se preocupar com o que, por muito tempo, lhe foi considerado como "exterior" - questão que, para a análise do discurso, não se configura como uma relação de "dentro" e "fora", uma vez que a língua não reflete algo das organizações sociais, ela as constitui e é, ao mesmo tempo, constituída por elas.

No entanto, muitas atividades tomam os usos da língua como neutros e transparentes, sem questionamentos acerca de seus "significados sociais, culturais, históricos e políticos". Nesses casos, o uso de textos "autênticos" (ou seja, coletados em sua situação real de uso) e, algumas vezes, de frases aparentemente geradas para o fim específico proposto serve tão somente ao exercício de alguma forma linguística específica, sem espaço para debates sobre sua inscrição discursiva. Veja-se este dado:

${ }^{7} \mathrm{Na}$ época, esse antropólogo sueco realizou um estudo sobre os chamados “interculturalistas", e mostrou que os conceitos mobilizados por eles a partir da antropologia eram, em sua maioria, dos anos 30 e 50; sua hipótese para a continuidade de seu uso no "campo intercultural" [intercultural domaine] quando já haviam caído em desuso na antropologia há várias décadas foi, justamente, a do direcionamento ao mercado de consumo e suas necessidades (Dahlén, 1997 apud DERVIN, 2014). 


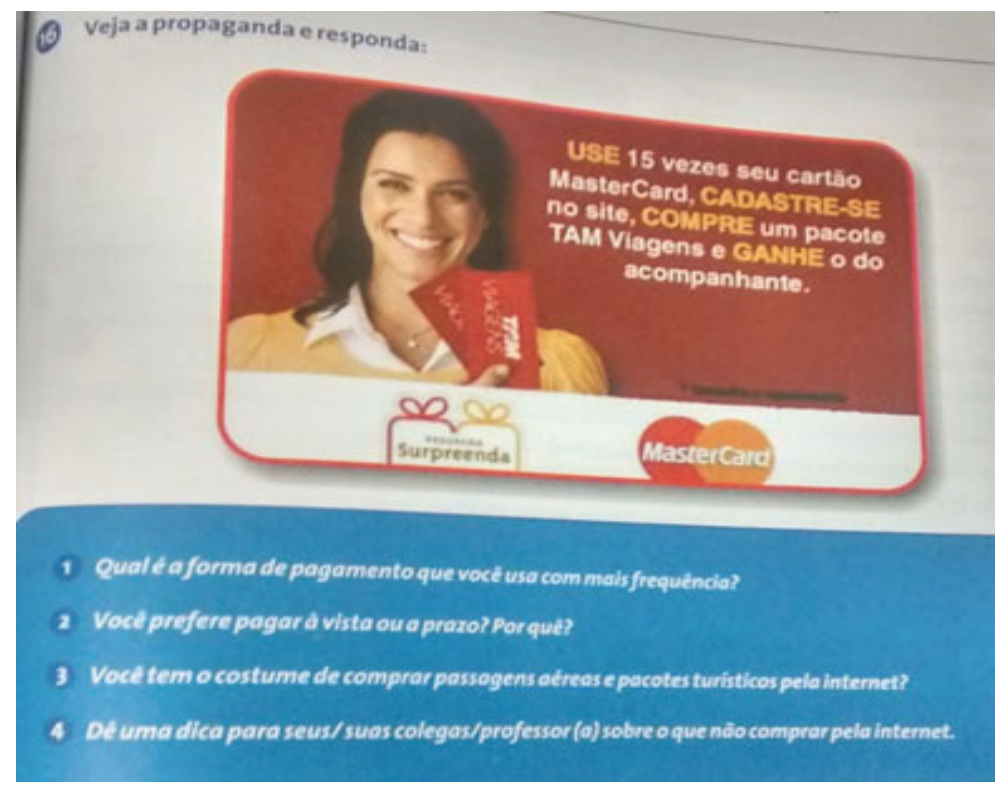

Figura 1: propaganda de cartão de crédito - exercício proposto pelo livro do estudante do Ciclo Básico na Unidade 5, "Sonho de consumo", Bloco 2, "Compras a um clique" (MOREIRA; BARBOSA; CASTRO, 2014, p.95)

Embora o posicionamento mostrado na apresentação do livro seja o de uso de "materiais autênticos", o que é confirmado na análise de Gonzáles (2015, p.110) ao afirmar que "todo o insumo é de fontes autênticas", há muitas ocorrências de textos (artigos, diálogos, e-mails) sem nenhuma referência à fonte de sua coleta. No exercício acima, ainda que seja disponibilizada uma peça publicitária em circulação efetiva, não há menção ao suporte original de sua publicação ou de outros aspectos implicados na sua difusão social. Na mesma página, na tarefa anterior, baseada em áudio, é utilizada uma reportagem que tampouco é referenciada, nem no livro, nem no site da coleção - onde é disponibilizada aberta e gratuitamente para uso dos professores ${ }^{8}$.

De saída, pode-se discutir a noção de texto que subjaz à seleção: importa mais o enunciado linguístico - no caso, evidentemente destinado à abordagem do modo imperativo em português brasileiro - do que o texto em seu regime específico de genericidade, inscrito em um determinado suporte - o que condiciona sua circulação, sua comunidade de leitores, a produção dos sentidos. Além disso, a necessidade de induzir a construção de frases com o imperativo serve-se, sem qualquer consideração, de um discurso do temor que dá sustentação à pergunta 4 , segundo a qual há certamente coisas que não se devem comprar por esse meio.

${ }^{8} \mathrm{O}$ áudio, "Comprar pela internet exige cuidados”, está disponível em http://brasilintercultural. com.ar/c_basico_estudio_audio.php, na Unidade 5. 
Registre-se, ainda, que nesse exercício, que não discute as conjunturas ou circunstâncias em que se ancoram os enunciados, privilegiando a abordagem de uma estrutura da língua ao induzir o uso do imperativo num aconselhamento, o que se poderia entender por privilégio de uma abordagem linguística conservadora não encontra eco na pergunta 2 , em que a falta de paralelismo na estruturas "à vista" / "a prazo" não atende às prescrições em vigor na constituição desse posicionamento, assumindo-se, sem quaisquer observações ou explicações, um uso corrente bastante consagrado: raramente se diz "ao prazo" ou se escreve "a vista" sem o acento grave.

Este outro exercício, retirado da Unidade 1 - "Interagindo em português", se baseia em dois diálogos (2014, p.12) cujas referências não são dadas, e pede que se relacionem "palavras e expressões com o mesmo sentido":

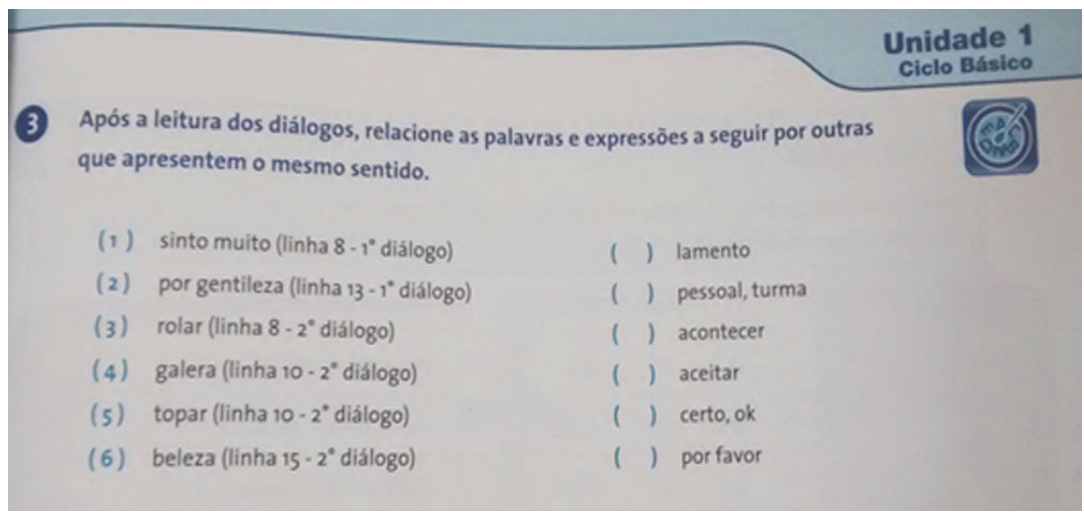

Figura 2: relacionar palavras e expressões - exercício proposto pelo livro do estudante do Ciclo Básico na Unidade 1, "Interagindo em português", Bloco 1, "Ao telefone" (MOREIRA; BARBOSA; CASTRO, 2014, p.13)

Se "resolvermos" o exercício, verificaremos que as respostas esperadas são:
(1) sinto muito $=$ lamento
(4) topar = aceitar
(2) por gentileza $=$ por favor
(5) beleza $=$ certo, ok
(3) rolar = acontecer
(6) galera $=$ pessoal, turma

As expressões (1) e (2) e seus correspondentes, embora apresentem, também, nuances semânticas que as diferenciam, parecem ser menos problemáticas que as outras. Afirmar que "rolar" e "acontecer" ou "topar" e "aceitar" significam igualmente é ignorar o funcionamento da língua como código linguageiro, ou seja, como constitutivo dos sujeitos na construção de sua própria identidade nas várias comunidades discursivas de que participam. Os níveis de registro não são comentados, homologam-se termos cujos traços semânticos podem ser intercambiados em diversas circunstâncias, mas não sem que se registrem informalidade, intimidade ou pertencimento social, por exemplo. Ignora-se, assim, a dimensão identitária dos usos da língua. A dificuldade encontrada pelo estrangeiro em vivenciar essas nuances é bem mostrada por Christine Revuz, quando afirma que 
contrariamente ao que se passou na língua materna, o aprendiz não tem a cabeça repleta de frases feitas... por outros. Para falar, ele deve, em sentido estrito, fazer frases. Ele se encontra compelido a um verdadeiro trabalho de expressão, a um questionamento permanente sobre a adequação daquilo que diz àquilo que quer dizer. As formas ocas da língua, estereótipos que permitem falar para não dizer nada ou para dizer como todo o mundo, são adquiridas tardiamente, através de uma identificação forçosa com os locutores nativos, seu modo de pensamento, seus costumes. (REVUZ, 1997, p.227; destaque nosso).

Ressalte-se, ainda, que no próprio enunciado há uma regência agramatical: "relacione as palavras e expressões a seguir por outras que apresentem o mesmo significado". A preposição por causa estranheza como introdutora de complemento do verbo relacionar pois é improdutiva nessa regência em português brasileiro; a função de associação, nesse caso, é exercida preferencialmente pela preposição $a$ ou com (cf. NEVES, 2003). E cabe observar, diante disso, que o foco da atenção do estudante possivelmente está nos enunciados que deve relacionar, isto é, na "resolução" do exercício, mas sua atenção periférica percebe e apreende as estruturas das consignas: num material instrucional, tomam-se como default as estruturas com as quais ele instrui.

Além disso, é interessante notar que, no diálogo a partir do qual o exercício é desdobrado, um dos enunciados traz um índice de contágio do espanhol: um dos locutores diz ao telefone: "Sou Valdomiro, paciente do Doutor Jorge" (2014, p.12). Enquanto no espanhol "standard" a forma /soy + nome próprio/ é largamente empregada, nos usos correntes do português brasileiro o mais comum é referirse a si mesmo em terceira pessoa: "[é] o Valdomiro", “[quem está falando é] o Valdomiro", etc.

Consideradas essas ocorrências, logo se entende que a língua é um lugar constitutivo de produção de sentidos que marca o sistema cultural no qual o sujeito se institui, e é por ele marcada. Isso confirmaria que o discurso se constitui não só a partir da dupla determinação pelo inconsciente e pela ideologia, conforme se postula no quadro teórico aqui mobilizado, mas também pelo papel exercido pela cultura como espaço de referência e de interpretação na formação do indivíduo. Por isso, seria necessário considerar a inscrição do discurso em uma ordem da cultura, na qual

(...) entraria o universal e o singular, os grupos sociais e o indivíduo na sua relação com eles. Sua materialidade significante poderia ser constituída de linguagens não restritas às formas de expressão verbal, da oralidade e da escrita, pois as culturas chegam a nós pelas imagens, movimentos corporais, gestos, olhar. (LEANDRO FERREIRA, 2011, p.60).

Mas aquilo que é mostrado nos livros didáticos muitas vezes se pauta em um imaginário generalizador que não dá margem à constituição dessa identidade por meio do contato com vários outros, dos quais seria possível se aproximar ou se afastar. Nossa tradição escolar pressupõe uma estabilização dos sentidos, construídos a partir de lugares discursivos específicos apresentados como universais. Como atesta Kramsch, 
Even though everyday cultural practices are as varied as a native speaker's use of language in everyday life, the focus is on the typical, sometimes stereotypical, behaviors, foods, celebrations and customs of the dominant group or of that group of native speakers that is the most salient to foreign eyes. (KRAMSCH, 2013, p.66, destaque nosso)

Um traço desses pertencimentos específicos pode ser observado em outro dado, que, embora tenha sido retirado da mesma unidade, não mantém relação direta com o tema do bloco, em que são tratadas questões relativas a necessidades comunicacionais do dia a dia - consultas médicas, marcação de encontros, números de telefone, cumprimentos, despedidas, etc.:

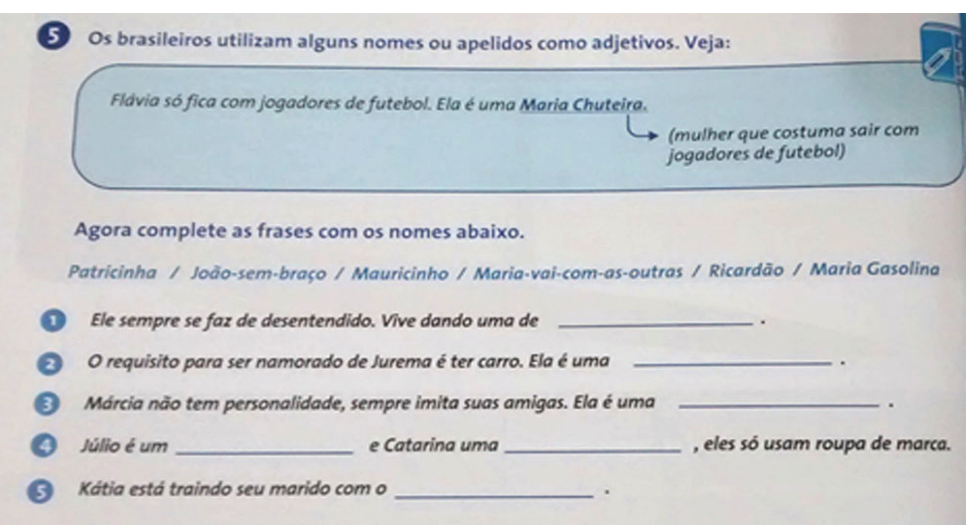

Figura 3: exercício sobre nomes e apelidos proposto pelo livro do estudante do Ciclo Básico na Unidade 1, "Interagindo em português", Bloco 1, "Ao telefone" (MOREIRA; BARBOSA; CASTRO, 2014, p.16)

No enunciado, uma asseveração a partir da qual se convidará o estudante a completar afirmações derivadas, a "convenção uma língua = uma cultura" (KRAMSCH, 2013, p.66) é reforçada pelo artigo definido plural que antecipa o substantivo "brasileiros". O plural aqui homogeniza, é totalizante. "Os brasileiros" são construídos como um coletivo de contornos claros, que se caracteriza por usar "nomes ou apelidos como adjetivos", e isso aparece como um fato, está dado.

Em termos de discurso, o ato de nomear é um aspecto particularmente interessante de ser observado. Ao dar nome a algo, nos inscrevemos necessariamente em uma memória marcada pelos já-ditos, pelos enunciados que circulam numa dada organização social - conforme a célebre formulação, algo sempre fala antes e alhures. Do mesmo modo, vale dizer que, ao reproduzir como neutros nomes mobilizados por certos discursos, o material valida sua circulação e colabora para sua permanência.

Os nomes escolhidos para esse exercício se inscrevem em uma memoriabilidade que reproduz um aspecto flagrante das práticas sociais não só no Brasil, mas predominante em diversos países: a superficialização da mulher e a construção de sua dependência em relação ao masculino. Dos sete nomes escolhidos, os quatro que dizem respeito ao feminino - maria chuteira, patricinha, maria-vai-com-as-outras 
e maria gasolina - reforçam esse imaginário sem nenhuma observação sobre estereótipos, por exemplo. No caso do masculino, inversamente, há a reprodução do imaginário do homem-garanhão, o "Ricardão", que a "mulher traidora" tem como amante. Esse dado é particularmente interessante quando confrontado com o que aparece na Apresentação do livro, mais de uma vez, como dissemos, com o uso de marcadores de gênero entre parênteses, indicativo de uma adesão ao discurso de igualitarismo, possivelmente obrigatória num material que se põe como politicamente adequado, moralmente correto, afinado com discursivizações hegemônicas no campo dos estudos da educação, etc.

Ainda no âmbito mais explicitamente relacionado ao que possa ser referido por "cultural", outra atividade do livro desvela um atravessamento identitário da instância autoral:

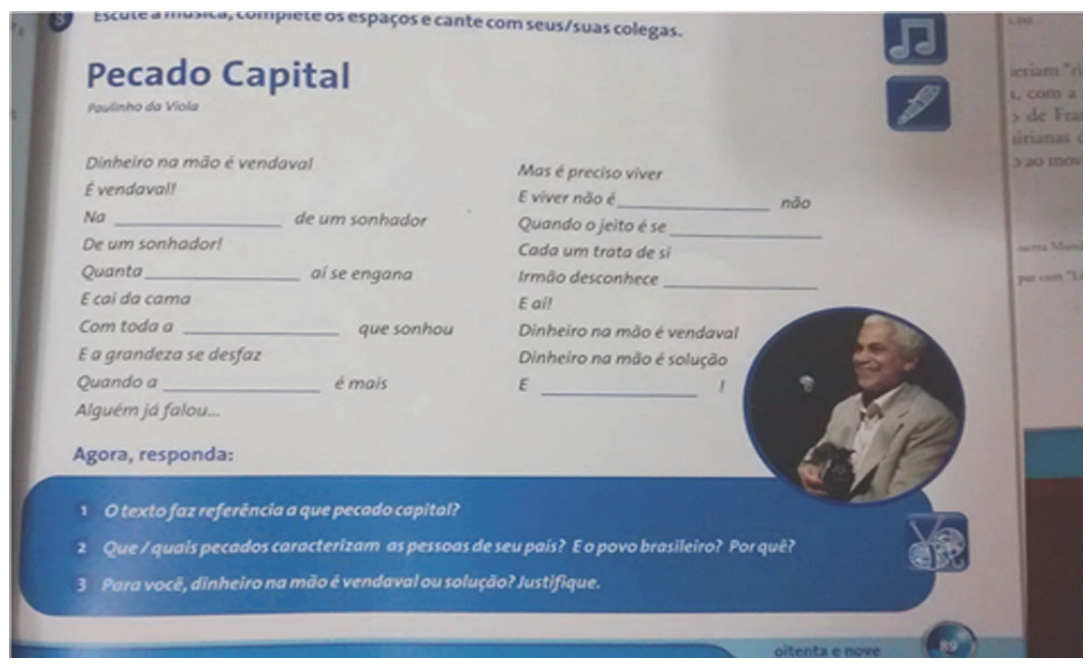

Figura 4: exercício de "completar espaços" com a música Pecado Capital proposto pelo livro do estudante do Ciclo Básico na Unidade 5, "Sonho de consumo", Bloco 1,

"Dinheiro na mão é vendaval" (MOREIRA; BARBOSA; CASTRO, 2014, p.89)

As perguntas sobre a canção, assim como sua escolha para compor o exercício dentro do tema proposto pela unidade, relacionado de uma forma ampla ao "dinheiro", projetam como certo o conhecimento do que seja um "pecado" e, mais especificamente, um "pecado capital", pilares da tradição judaico-cristã. Do mesmo modo, a pressuposição linguística presente na segunda questão - de que os pecados não só existem, mas também de que alguns deles caracterizam as pessoas do país do estudante e também o povo brasileiro - é um rastro dos discursos religiosos que condicionam a produção desse exercício.

Esses tipos de tarefa, instituídos com a abordagem do ensino comunicativo e da necessidade da "cultura" no ensino de línguas, parecem ilustrar o que De Certeau já anunciava sobre a presumida neutralidade do "cultural", ainda que sem tratar especificamente dessa área: 
Quando não se encerra na estatística e na precisão analítica dos dados, o discurso cultural cai nas generalidades e reaplica resíduos doutrinais (políticos, filosóficos, religiosos). Esse discurso universal é o museu onde se reinstalam alguns conceitos extraídos de sistemas que tinham outrora seu rigor ('humanismo' etc.). A ideologia ressurge assim, sub-repticiamente, no cultural - uma ideologia de bricolagem, um saco ideológico, mas que anuncia, sem dúvida, uma outra coisa. (DE CERTEAU, 2012, p.199, destaque nosso)

Isso se pode verificar também na genealogia das sistematizações mais formalizadas desse material. No âmbito da pesquisa acadêmica realizada hoje, muitas foram as descobertas em termos de descrição do funcionamento das estruturas linguísticas e de suas variedades que superaram o paradigma normativo tradicional, e que são convocadas na "Apresentação"; no entanto, poucas delas são incorporadas no ensino nas atividades propostas ao estudante.

No que tange ao estudo do sistema verbal, por exemplo, eixo de um funcionamento que marca pessoa, número e modo, são incorporados os índices você, de $2^{\mathrm{a}}$ pessoa do singular, e a gente, de $1^{\mathrm{a}}$ pessoa do plural, o que aponta uma mudança em relação a materiais mais tradicionais que surpreendentemente ainda não os reconhecem, mesmo que largamente mais utilizados que as formas canônicas "tu" e "nós" (cf. BAGNO, 2011). O tu, por sua vez, é mostrado em uma linha à parte:

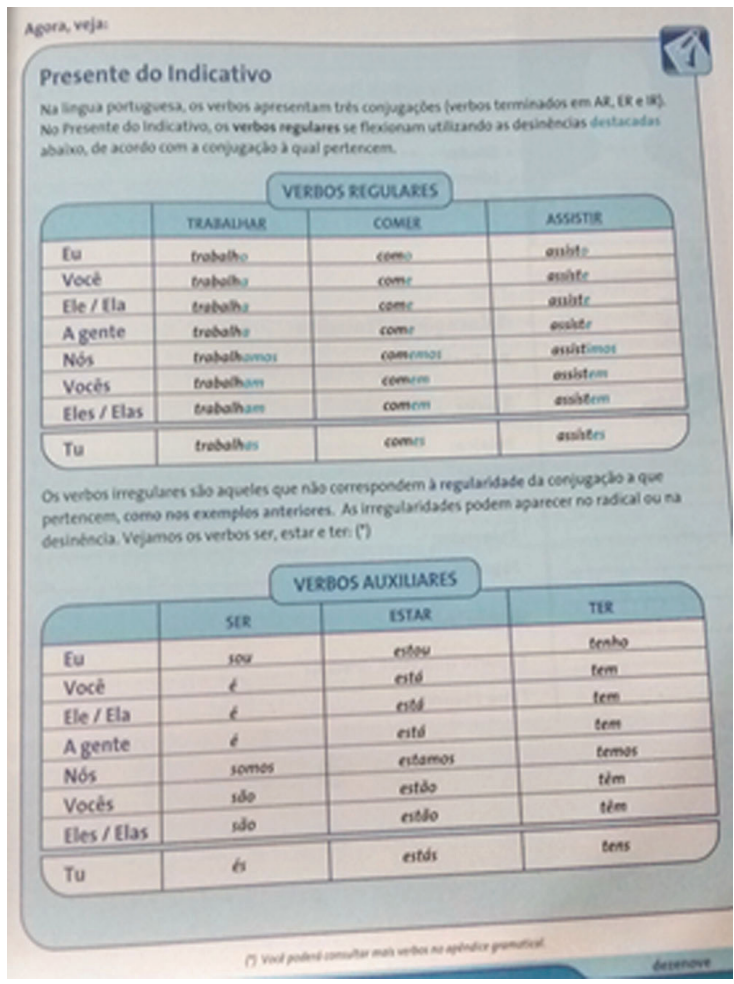

Figura 5: explicação sobre o presente do indicativo, primeira sistematização relacionada a verbos do livro do estudante do Ciclo Básico, localizada na Unidade 1, "Interagindo em português",

Bloco 2, "Redes sociais" (MOREIRA; BARBOSA; CASTRO, 2014, p.19) 
Enquanto incorpora um dado que pode ser fartamente observado pelos estudantes de português no espaço público, o material deixa variações mais sutis à margem. Não explica, por exemplo, a relação da produção ou não dos plurais com o monitoramento estilístico e com as variedades de maior ou menor prestígio social. Também não explicita a possibilidade da conjugação do tu conforme a não-pessoa do singular ( $t u$ é, tu está, $t u$ tem etc.) muito característica de variantes regionais.

Esse processo de apagamento atua também em outras sistematizações. A forma do gerúndio, por exemplo, é reduzida à sua ocorrência com auxiliares e à função de "descrever ações contínuas que ainda não acabaram", deixando inexplicada a complexidade de seu funcionamento em muitas outras ocorrências possíveis - alguns exemplos cotidianos dados por Bagno (2011, p.724) são "tire essa mancha com água fervendo", "Rosnando, o cachorro avançou sobre Ana", "Vamos nessa, pessoal, sambando".

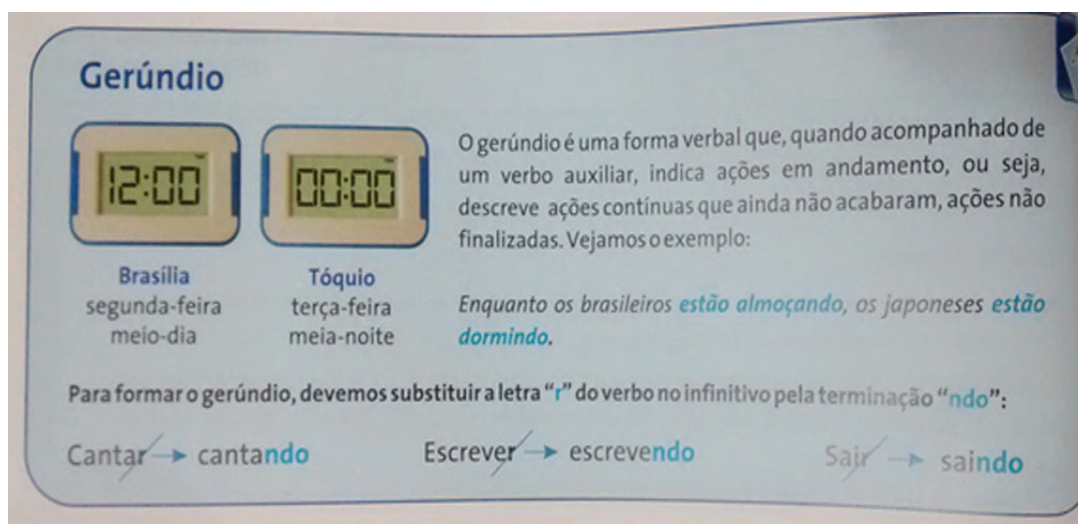

Figura 6: explicação sobre a forma do gerúndio no livro do estudante do Ciclo Básico, localizada na Unidade 2, "Quebrando a rotina", Bloco 2, "Hábitos cotidianos" (MOREIRA; BARBOSA; CASTRO, 2014, p.38)

A fonética, por sua vez, parece trazer algumas inovações, segundo estudo realizado a esse respeito, tendo como parte do córpus o ciclo básico da coleção Brasil Intercultural. Considera, por exemplo, a neutralização de pós-tônica final, como em estudante e caro, realizadas como [i] e [u], respectivamente, o que indicia um discurso progressista sobre os usos da língua no material. Ao mesmo tempo, ainda não traz nenhuma explicação sobre a variação das vogais átonas, principal motivo de crítica pelos autores: "caberá ao professor o discernimento para reconhecer, como igualmente apropriadas, produções tais como ' $\mathrm{m}$ [i]nino' para 'menino', bem como 'b[u]neca' para 'boneca'” (ALVES; SILVA, 2013, p.148).

Diante disso, ainda que haja muito a ser analisado para que se chegue a uma efetiva circunscrição do entrecruzamento de discursos nesse livro didático, as análises que fizemos parecem nos permitir sustentar a hipótese de que, assim como predomina uma generalização da "cultura brasileira", prevalece uma correspondente sistematização linguística que prioriza preceitos que sustentam um imaginário conservador de língua. 


\section{CONSIDERAÇÕES FINAIS}

Sabidamente, os materiais didáticos publicados por instituições legitimantes são largamente empregados como vias neutras - e por isso fiáveis - de acesso ao ensino e à aprendizagem de línguas. No caso em tela, a partir da análise de diversas atividades propostas pelo livro do estudante do ciclo básico da coleção Brasil Intercultural, buscamos considerá-los como suportes que se constituem na articulação de técnicas e normas, as quais, embora produzam um efeito de neutralidade e consenso, são sempre formalizações de práticas oriundas de comunidades específicas, discursividades produzidas por sujeitos e que produzem subjetivação (cf. SALGADO, 2013).

Dessa perspectiva, atendendo ao chamado de De Certeau (2012), parecenos que a virada a ser buscada no ensino de línguas e nos materiais instrucionais é, antes de tudo, de posicionamento: uma politização necessária. O salto dado por algumas gramáticas na última década (entre outros trabalhos, os renomados MOURA NEVES, 2003; BAGNO, 2011; POSSENTI, 2011), que abordam a língua de uma perspectiva científica engajada, que não ignora suas especificidades e que preza pela descrição de sua diversidade, parece não ter saído ainda do âmbito da circulação acadêmica, chegando não só às nossas escolas, mas às equipes editoriais, que frequentemente desconhecem o posicionamento que leva em conta as várias formas de habitar "o" português brasileiro e o que se pode entender por "cultura brasileira". Conforme defende Salomão, na esteira de outros pesquisadores da área,

o componente cultural no ensino de línguas tem muitas vezes enfocado prescrições comportamentais e informações sobre o outro, geralmente envoltos em uma visão de compreensão e ausência de conflitos, recusando-se a ser ideológico e minimizando a problematização (SALOMÃO, 2015, p.361).

Trata-se, enfim, de efetivamente assumir posicionamentos, uma vez que não há neutralidade possível, e que a proficiência dos estudantes de uma língua estrangeira só se estabelece quando, ao habitar essa língua, lidam com o código linguageiro convocado em cada texto, como identidade mesma do texto, da fonte que o fia e do estudante como seu interlocutor.

Parece possível dizer, por ora, que os posicionamentos em confronto neste material - que nos parece emblemático, nesta altura da pesquisa, dos confrontos característicos da produção editorial hoje - delimitam-se reciprocamente num jogo de forças verificável mais amplamente, no qual se impõe a consideração da pluralidade como variedade e diversidade, e da singularidade como parte disso, mas prevalecem estigmas não verbalizados, não explicitados, e que, por isso mesmo, relativamente apaziguados nos pré-construídos, pautam posicionamentos que entendem a inclusão do outro como transformação dele num duplo de si mesmo. 
SALGADO \& BOSCHI - Língua, cultura e imaginários: singular e plural em conflito ...

\section{REFERÊNCIAS BIBLIOGRÁFICAS}

ALVES, Ubiratã Kickhöfel; SILVA, Susieli Machry. M[e]nino ou m[i]nino? Bol[o] ou bol[u]? O tratamento das vogais do português brasileiro (LE) por manuais voltados a aprendizes argentinos. Linguagem \& Ensino, Pelotas, v.16, n.1, p. 131-153, jan./jun. 2013. Disponível em: http://www. rle.ucpel.tche.br/index.php/rle/article/view/798. Acesso em 5 de janeiro de 2015.

BAGNO, Marcos. Gramática pedagógica do português brasileiro. São Paulo: Parábola Editorial, 2011a.

BAGNO, Marcos.. O que é uma língua? Imaginário, ciência \& hipóstase. In: LAGARES, Xoãn; BAGNO, Marcos (org.). Políticas da norma e conflitos linguísticos. São Paulo: Parábola Editorial, 2011b.

CARVALHO, Orlene Lúcia S.; BAGNO, Marcos. Gramática brasileña para hablantes de español. $1^{\mathrm{a}}$ ed. São Paulo: Parábola Editorial, 2015.

DE CERTEAU, Michel. A cultura na sociedade. In: . A cultura no plural. Trad. Enid Abreu Dobránszky. $7^{a}$ ed. Campinas, SP: Papirus, 2012. p.191-220. Publicação original: 1993.

DERVIN, Fred. Cultural identity, representation and othering. In: JACKSON, J. The Routledge Handbook of Language and Intercultural Communication. NewYork: Routledge, 2014. p. 181194.

GONZALEZ, Verónica A. Análise de abordagem de material didático para o ensino de línguas (PLE/PL2). Dissertação de Mestrado - Departamento de Línguas Estrangeiras e Tradução da Universidade de Brasília. Brasília, 2015. 170p.

HOLLIDAY, Adrian. Culture as constraint or resource: essencialist versus non-essencialist views. In: GRAY, K., ANSELL, M., CARDEW, S. and LEEDHAM, M., eds. The Japanese Learner: Context, Culture and Classroom Practice. Oxford: Oxford University Press, 2001. p. 38-40. Disponível em: http://owww.brookes.ac.uk/schools/education/eal/jl-archive/ jl-bestof/18.pdf. Acesso em 25 de agosto de 2015 .

JÚDICE, Norimar. Identidade brasileira em material para ensino de português a falantes do alemão. In: MEYER, RM; ALBUQUERQUE, A. Português para estrangeiros: questões interculturais. Rio de Janeiro: Ed. PUC-Rio, 2013.

KRAMSCH, Claire. Language and culture. In: SIMPSON, J. (Ed.). The Routledge Handbook of Applied Linguistics. New York: Routledge: 2011a. p. 305-317.

KRAMSCH, Claire. The symbolic dimensions of the intercultural. Language Teaching. Cambridge University Press, v. 44, p. 354-367, July 2011b. Disponível em: <http://journals.cambridge.org/ action/displayAbstract?fromPage $=$ online $\&$ aid $=8271738>$. Acesso em 22 de setembro de 2015 .

KRAMSCH, Claire. Culture in foreign language teaching. Iranian Journal of Language Teaching Research 1(1), Jan. 2013, p. 57-78. Disponível em: http://www.urmia.ac.ir/sites/www.urmia. ac.ir/files/Article\%204_1.pdf. Acesso em 5 de janeiro de 2015.

LAGARES, Xoãn; BAGNO, Marcos (org.). Políticas da norma e conflitos linguísticos. São Paulo: Parábola Editorial, 2011.

LEANDRO FERREIRA, Maria Cristina. O lugar do social e da cultura numa dimensão discursiva. In: INDURSKY, Freda; MITTMANN, Solange; LEANDRO FERREIRA, Maria Cristina (org.). Memória e história na/da Análise do Discurso. Campinas: Mercado das Letras, 2011, p.55-64. 
LIDDICOAT, Anthony. Language Teaching and Learning from an Intercultural Perspective. In: HINKEL, E. Handbook of Research in Second Language Teaching and Learning. Vol. II. New York: Routledge, 2011. p. 837-855.

MAIngueneAU, Dominique; CHARAUDEAU, Patrick. Dicionário de análise do discurso. 2.ed. São Paulo: Contexto, 2008. Publicação original: 2004.

MAINGUENEAU, Dominique. Discours. Intertextualité. Interlangue. In: Champs du signe, n.13/14, p.197-210, 2002.

MAINGUENEAU, Dominique. Gêneses do Discurso. Trad. Sírio Possenti. Curitiba: Criar, 2005.

MAINGUENEAU, Dominique. Discurso Literário. Trad. Adail Sobral. São Paulo: Contexto, 2006.

MOREIRA, Aline; BARBOSA, Cibele Nascente; CASTRO, Giselle Nunes. Coord: MENDES, Edleise. Brasil Intercultural: Língua e Cultura Brasileira para Estrangeiros: ciclo básico, níveis 1 e 2. Buenos Aires, Argentina: Casa do Brasil, 2014. Publicação original: 2013.

NEVES, Maria Helena M. Gramática de usos do português. 2ª ed. São Paulo: Ed. Unesp, 2003.

OLIVEIRA, Gilvan M. Política linguística e internacionalização: a língua portuguesa no mundo globalizado do século XXI. Trabalhos em Linguística Aplicada. [online]. Vol.52, n.2, pp. 409433, 2013.

POSSENTI, Sírio. Questões de linguagem: passeio gramatical dirigido. $1^{\text {a }}$ ed. São Paulo: Parábola, 2011.

REVUZ, Christine. A língua estrangeira entre o desejo de um outro lugar e o risco do exílio. In: SIGNORINI, Inês (Org.). Língua(gem) e identidade. São Paulo: Mercado de Letras, 1998. p.213-230.

SALGADO, Luciana S. Ritos genéticos editoriais: autoria e textualização. São Paulo: Annablume; Fapesp, 2011.

SALGADO, Luciana S. Cibercultura: tecnoesfera e psicoesfera de alta potência difusora. In: ABRIATA, V. L. R.; CÂMARA, N. S.; RODRIGUES, M. G.; SCHWARTZMANN, M. N. Leitura: a circulação de discursos na contemporaneidade. Franca, SP: Unifran, 2013. p.103-123.

SALOMÃO, Ana Cristina B. O componente cultural no ensino e aprendizagem de línguas: desenvolvimento histórico e perspectivas na contemporaneidade. Trabalhos em Linguística Aplicada [online]. 2015, vol.54, n.2, pp. 361-392. Disponível em: http://dx.doi.org/10.1590/010318134500150051 . Acesso em 5 de março de 2016.

WELSCH, Wolfgang. Transculturality: The puzzling form of cultures today. California Sociologist, v. 17 \& 18, p. 19-39, 1994. Disponível em: http://www2.uni-jena.de/welsch/papers/W_Wlelsch_ Transculturality.html. Acesso em 5 de setembro e 2015.

ZOPPI FONTANA, Monica G.; DINIZ, Leandro R. A. Declinando a língua pelas injunções do mercado: institucionalização do português língua estrangeira (PLE). Estudos Linguísticos. São Paulo, v. 37, p. 89-119, 2008. 